tolerar passivamente os ignorantes: o sábio deve aspirar a difundir o "uso público da razão". S. Zac pôs claramente essa questão: também o sábio, que se nutre da verdade, obrigado a viver entre os não sábios, deve defendê-la em nome da verdade a que aspira e a que, em princípio, todos podem aceder. Essa liberdade de pensar abre uma via para a vida verdadeiramente humana (Zac 13, p. 3).

14. É no âmbito do direito positivo que Espinosa reconhece como noção apropriada o "pecado". Não se trata de uma noção moral ou teológica, como podem ilustrar as seguintes palavras de Espinosa: "Pelo dito entendemos facilmente que no estado de natureza não há nada que seja bom ou mau pelo acordo de todos; pois todo aquele que está no estado natural olha tão só para sua utilidade e decide, segundo seu engenho e tendo em conta sua utilidade, o que é bom e o que é mau, e não está obrigado por lei alguma a obedecer a ninguém, fora ele mesmo; daí que no estado natural não seja concebível o pecado. Porém sim no estado civil, onde por comum acordo se decide o que é o bem e o que é o mal, e cada um está obrigado a obedecer ao Estado. O pecado não é outra coisa que a desobediência, a qual é castigada pelo direito do Estado.”

(Espinosa 2, IV, P38, esc. 2, p. 210).

\section{A CONCEPÇÃO DE NATUREZA HUMANA EM} BENEDICTUS DE SPINOZA*

\section{Emanuel Angelo da Rocha Fragoso**}

Resumo: Spinoza concebe a natureza humana em sua obra Ethica como constituída por modos de dois dos infinitos atributos de Deus, o pensamento e a extensão, ou a ideia e seu objeto, o corpo, respectivamente. A mente humana, enquanto essencialmente uma ideia, e o objeto desta ideia, o corpo, pressupõe uma relação não causal entre um modo finito do atributo pensamento e do atributo extensão. O corpo, enquanto certa relação composta ou complexa de movimento e de repouso se mantém através de todas as mudanças que afetam suas partes, está continuamente sujeito ao acaso dos encontros (occursus), ou ao impacto dos múltiplos e variados corpos a sua volta. A mente reflete estes encontros e através deles, ou das afecções corporais, conhece os corpos externos. É a ideia-afecção. É o conhecimento imaginativo, ou o conhecimento condicionado pela situação de nosso próprio corpo, por nosso temperamento, nossa experiência prévia e nossos preconceitos.

Palavras-chave: Spinoza. Ethica. Natureza humana. Mente. Corpo.

\section{Introdução}

Há milênios a alma é considerada o suporte místico de inúmeras seitas, religiões e assemelhados, e como tal, é tida como sendo em muito superior ao corpo, seja quanto à sua infinitude, em oposição à finitude do corpo, seja quanto às suas funções, de controle ou de comando sobre o

* Este texto é uma versão modificada e ampliada de nossa Palestra apresentada no Colóquio Natureza e Linguagem, realizado no período de 12 a 14 de setembro de 2006, na Universidade Federal do ceará - UFC. ** Universidade Estadual do Ceará - UECE 
corpo, que seria por sua vez, comandado por ela. Para Spinoza, a alma, ou melhor, a mente ${ }^{1}$, é apenas a ideia do corpo. E este é um objeto realmente existente, ou seja, um modo do atributo extensão; e aquela, um modo do atributo pensamento. As relações entre estes modos não se dão num plano hierárquico ou causal, sendo somente possíveis graças ao que Spinoza vai denominar Paralelismo. Utilizando a Ética, obra culminante de Spinoza, elaborada por ele durante décadas e diversas vezes revisada, procederemos a uma análise desta relação entre a mente e o corpo, ou seja, daquilo que em Spinoza pode-se denominar de natureza humana.

\section{A natureza humana}

Em Spinoza, o homem é extensão e pensamento. E, analisar a natureza humana é analisar a essência do homem, pois, por definição, essência é "[...] aquilo que, se dado, a coisa é necessariamente posta e que, se retirado, a coisa é necessariamente retirada;" (Spinoza 1, E2Def2 e E2P10S2)2. Se o homem não é uma substância, segue-se que ele não existe necessariamente, visto sua essência não envolver a existência necessária, isto é, ele é um modo finito, o existir não pertence a sua natureza porque ele não é causa de si próprio. Neste caso, ele deve necessariamente ser concebido e existir por outro além dele mesmo, ou seja, o modo finito, em razão de sua finitude, não pode determinar por si mesmo a sua existência. No dizer de Spinoza: "A essência do homem não envolve a existência necessária, isto é, segundo a ordem da natureza tanto pode ocorrer que este ou aquele homem exista quanto que não exista." (Spinoza 1, E2Ax1). Ademais, nosso autor acrescenta explicitamente que o ser da substância não constitui a forma do homem (Spinoza 1, E2P10S1); ou seja, não há relação necessária entre a essência e a existência de todo ser que deva sua existência a uma causa exterior. Muito provavelmente fundamentado na Carta $X^{3}$, Léon Brunschvicg afirma que a análise da natureza humana não deve ser compreendida do ponto de vista da existência do homem, pois esta não nos levará à sua essência; e sim, compreendida em relação à sua causa eficiente que é Deus. (Brunschvicg 3, p. 55-58).

Nesta análise está pressuposta uma radicalidade entre substância e modo. Para Spinoza a distinção radical entre a substância e os modos, é justamente a causa sui, isto é, a essência da substância envolve sua existência. Assim, a univocidade dos atributos não implica nenhuma confusão de essências, visto que os atributos constituem a essência da substância, mas não constituem a dos modos. Segue-se que a essência do homem não pode ser posta diretamente pela substância absolutamente infinita ou pelos atributos que são infinitos em seu gênero, pois senão o homem seria necessariamente dado e também existiria necessariamente. Todavia, a natureza humana não pode existir e nem ser concebida sem os atributos que são, em certo sentido, a própria substância. Donde, resulta necessariamente que a essência do homem - ou sua natureza - é constituída por modificações definidas dos atributos de Deus (Spinoza 1, E2P10C)4.

Brunschvicg corrobora esta afirmativa ao considerar que a determinação da relação que liga o homem a Deus, supõe a Ciência do homem e não a Ciência de Deus, porque uma relação não pode ser estabelecida sem que os dois termos sejam igualmente conhecidos. Dentro desta perspectiva, este autor vai considerar o problema inicial que se impõe na análise da essência do homem ou a relação que liga este à sua causa eficiente: se Deus é um ser absolutamente indeterminado, ele não pode ser a razão de nenhuma determinação; logo, a essência do homem não pode ser determinada diretamente, como uma consequência da natureza divina ou do sistema eterno das coisas, ou seja, a substância infinita, em razão de sua infinitude, não pode justificar a existência deste ou daquele modo 
finito. Para Brunschvicg, a essência do homem deve ser determinada com a utilização de "auxiliares", a observação sensível ou a experiência, que atuarão provisoriamente como um ponto de partida desta Ciência humana. (Brunschvicg 3, p. 55-58).

Esta postura de Brunschvicg tem o aval de Victor Delbos em sua obra Le problème moral dans la Philosophie de Spinoza et dans l'Histoire $d u$ spinozisme (Delbos 5, Cap. IV, p.72). No entanto, em sua outra obra, $O$ Espinosismo, ao referir-se ao uso da experiência por Spinoza, quando da determinação dos caracteres principais da natureza humana, condiciona este uso à explicação racional, logo a seguir, daquilo que a experiência mostrou a Spinoza (Delbos 6, p. 84). Segundo Delbos, desta experiência ou observação sensível, Spinoza retém certos fatos gerais incontestáveis aos quais nomeia de "axiomas". A utilização deste nome para os "fatos gerais incontestáveis" retidos da experiência, iguala estes às proposições gerais imediatamente evidentes que devem ser admitidas sem demonstração; ou seja, os fatos gerais retidos da experiência têm o mesmo valor dos "verdadeiros axiomas" da Ética, pois este nome até então só fora utilizado por Spinoza para a denominação das "proposições gerais imediatamente evidentes que são admitidas sem demonstração". Segundo este mesmo intérprete, os fatos gerais incontestáveis retidos da experiência são os axiomas da Parte 2 da Ética (no início): o axioma número 2 "O homem pensa.", o número 4 "Sentimos que um certo corpo é afetado de muitas maneiras." e o número 5 "Não sentimos nem percebemos nenhuma outra coisa singular além dos corpos e dos modos do pensar." (Delbos 6, p. 84).

\subsection{A mente humana}

Se a natureza humana é constituída de modos dos atributos de Deus, se estes atributos são concebidos por si e o conhecimento de um não pode ser deduzido do outro, ainda que existam infinitos atributos, segue-se que só podemos conhecer dois dos atributos divinos: o atributo extensão e o atributo pensamento. Donde, a natureza do homem só pode ser definida como modos destes dois atributos. Ora, pelo axioma 2, citado acima, "O homem pensa.", segue-se então que ele é constituído por um modo do atributo pensamento: a ideia, pois, de todos estes modos é por natureza o primeiro e, sendo ela dada, os outros modos, aos quais ela é anterior, devem existir no mesmo indivíduo. Portanto, uma ideia é o que primeiramente constitui o ser atual da mente [mens] humana (Spinoza 1, E2P11D). Mas esta ideia não pode ser a ideia de algo que não existe realmente, pois neste caso a mente não seria uma ideia real, seria uma quimera ou um mero nada. Resultando que, se a mente do homem é uma ideia, ela necessariamente é uma ideia de algo que existe realmente (Spinoza 1, E2P11D).

Neste ponto, intervêm os axiomas citados acima, o axioma 4: "Sentimos que um certo corpo é afetado de muitas maneiras." e o axioma 5: "Não sentimos nem percebemos nenhuma outra coisa singular além dos corpos e dos modos do pensar.". Pelo primeiro, segue-se que as ideias de afecções de nossa mente necessariamente são de um certo corpo ou de um certo modo do atributo extensão; pelo segundo, segue-se a exclusão da possibilidade de qualquer outra coisa além do corpo ser o objeto da mente, ou seja, se a mente humana é uma ideia, se nós sentimos que um determinado corpo possa ser afetado e nós não sentimos nada além dos corpos e dos modos do pensar, então a mente do homem é uma ideia ou de um corpo determinado ou de um modo do pensamento. Ora, fora da ideia como modificação do pensamento, ou ideia que implica o conhecimento do seu objeto, nós não percebemos nada além dos corpos. Portanto, a mente humana é essencialmente uma ideia, e o objeto que constitui a mente humana é o corpo, isto é, um modo definido da extensão, existente em ato, e nenhuma outra coisa (Spinoza 1, E2P13D) 5 . 


\subsection{A relação entre a mente e o corpo}

Como vimos, a mente humana é uma ideia do corpo humano, ou seja, ela pressupõe uma relação entre um modo finito do atributo pensamento e um modo finito do atributo extensão. Também foi afirmado que os atributos são distintos entre si e cada um é concebido por si, isto é, eles mantêm sua heterogeneidade, ainda que sejam aspectos de uma mesma substância (Spinoza 1, E1P10). Se "O conhecimento do efeito depende do conhecimento da causa e envolve este último." (Spinoza 1, E1Ax4), os modos de cada atributo envolvem apenas o conceito do atributo do qual são modos e não o conceito dos demais atributos; segue-se que a ideia, enquanto modo do atributo pensamento, não pode ser causada pelo corpo, enquanto modo do atributo extensão, ou seja, a relação entre a mente e o corpo não pode ser considerada como uma relação de causalidade entre os atributos (ou inter-atributiva). No dizer de Spinoza: “Os modos de qualquer atributo têm Deus por causa, enquanto ele é considerado exclusivamente sob o atributo do qual eles são modos, e não enquanto é considerado sob algum outro atributo." (Spinoza 1, E2P6).

Desta recusa spinozista da causalidade inter-atributiva podemos extrair duas consequências: a recusa da explicação realista da produção das ideias e a recusa da interpretação idealista da produção das coisas, ou seja, a causalidade inter-atributiva é negada em suas duas vias, quer sejam os modos do atributo extensão considerados como causa dos modos do atributo pensamento, quer os modos do atributo pensamento sejam considerados como causa dos modos do atributo extensão. Quanto à primeira, na recusa da explicação realista da produção de ideias, Spinoza nega que a causa das ideias ou modos do atributo pensamento sejam o próprio ideado ou as coisas percebidas por estas ideias. Quanto à segunda, na recusa da interpretação idealista da produção das coisas, Spinoza nega que a causa das coisas ou modos do atributo extensão sejam ideias presentes anteriormente no ser divino que atuariam como modelos das coisas a serem produzidas.

A primeira recusa ocorre na proposição 5 da Parte 2 da Ética, na qual Spinoza considera especificamente as ideias como impossíveis de serem causadas pelos seus respectivos "seres formais", isto é, a causa da ideia do corpo ou da mente humana não é o corpo: “O ser formal das ideias reconhece Deus como sua causa, enquanto Deus é considerado apenas como coisa pensante, e não enquanto é explicado por outro atributo." (Spinoza 1, E2P5).

A segunda recusa ocorre no corolário da proposição 6, desta mesma Parte 2, no qual Spinoza afirma que "[...] as coisas ideadas se seguem e se deduzem de seus respectivos atributos, da mesma maneira, conforme mostramos, que as ideias se seguem do atributo do pensamento, e com a mesma necessidade.” (Spinoza 1, E2P6C); ou seja, a causa do corpo não é a mente humana ou a ideia deste corpo.

Excluída a possibilidade da relação causal inter-atributiva, restanos agora indagar acerca da verdadeira relação entre a mente e o corpo, pois se ambos remetem a seus respectivos atributos, então, qual a relação que se estabelece entre a mente e o corpo, ou entre a ideia e seu objeto?

\subsection{O Paralelismo}

Os modos de qualquer atributo que seja não envolvem mais que o conceito do atributo do qual são modos, pois os atributos da substância devem ser concebidos por si (Spinoza 1, E1P10). Assim, os modos do atributo extensão ou os corpos, e os modos do atributo pensamento ou as ideias, que constituem a natureza do homem, são modos pelos quais os atributos de Deus se exprimem de uma maneira definida e determinada (Spinoza 1, E1P25C). Donde, os corpos têm Deus como causa apenas 
enquanto ele é considerado sob o atributo extensão; da mesma maneira, as ideias têm Deus como causa apenas enquanto ele é considerado sob o atributo pensamento (Spinoza 1, E2P6). Portanto, ainda que os infinitos atributos e seus respectivos modos sejam heterogêneos e irredutivelmente distintos, suas determinações são subsumidas à mesma ordem e regras segundo a mesma relação. No dizer de Spinoza: "A ordem e a conexão das ideias é o mesmo que a ordem e a conexão das coisas" (Spinoza 1, E2P7).

Para Deleuze (Deleuze 4, p. 74-75), com o paralelismo, Spinoza estabelece uma identidade de ordem entre as ideias e os corpos ou isomorfia, isto é, a identidade entre as séries dos atributos da substância absoluta; e uma identidade de conexão entre as duas séries ou isonomia, isto é, os atributos produzem seus respectivos modos autonomamente, mas eles agem segundo um mesmo encadeamento e sob princípios iguais. Enfim, é estabelecida a identidade de ser ou isologia, isto é, a mesma coisa é produzida no atributo pensamento sob o modo de uma ideia e no atributo extensão sob o modo de um corpo.

Deleuze estabelece ainda uma distinção entre o paralelismo epistemológico e o paralelismo ontológico. O primeiro, ou o paralelismo epistemológico, está expresso na proposição 7, da Parte 2 da Ética, na sua demonstração e no seu corolário; este é descrito como o paralelismo que se estabelece entre a ideia e o seu ideato, e segundo Deleuze, nos conduz à simples unidade de um "indivíduo", formado pelo modo de certo atributo e a ideia que representa exclusivamente este modo. Este tipo de paralelismo implica a correspondência, a equivalência e a identidade entre um modo do pensamento e um modo tomado no seu atributo bem determinado, podendo ser expresso pela forma geral: um só e mesmo indivíduo é exprimido por certo modo e pela ideia que lhe corresponde, ou seja, a toda ideia corresponde qualquer coisa, pois nenhuma coisa poderia ser conhecida sem uma causa que a fizesse ser, e a toda coisa corresponde uma ideia, pois Deus forma uma ideia da sua essência e de tudo o que dela resulta. Considerado sob o aspecto das ideias e dos corpos, este paralelismo se desdobra num caso particular: o paralelismo psico-físico ${ }^{6}$.

O segundo paralelismo ou paralelismo ontológico está expresso no escólio da proposição 7, da Parte 2 da Ética; este é o paralelismo que se estabelece entre os modos de todos os atributos, modos estes que não se distinguem senão pelos atributos, ou seja, uma só e mesma modificação é exprimida por todos os modos correspondentes que diferem pelo atributo, ou seja, os modos de todos os atributos expressam, nos seus respectivos gêneros, uma única modificação da substância, à semelhança dos atributos distintos que expressam uma única substância.

Martial Gueroult por sua vez, vai distinguir o paralelismo epistemológico em dois tipos: o paralelismo extracogitativo e o paralelismo intracogitativo. O primeiro ou o paralelismo extracogitativo é "A ideia considerada como essência objetiva ou representação de uma coisa diferente de um modo do pensamento." (Gueroult 8, p. 70, grifo do autor), ou seja, este paralelismo é dotado de função representativa, pois se dá entre as ideias e os modos dos outros atributos não mentais. Este tipo de paralelismo é o fundamento da correspondência entre a ideia e o seu objeto e explica a necessidade desta relação de correspondência entre a ideia e o seu objeto, garantindo assim que toda ideia tenha seu objeto. O segundo ou o paralelismo intracogitativo, se dá no interior do próprio atributo pensamento de duas formas: (1) entre a ordem e a conexão das ideias e a ordem e a conexão das causas no interior do atributo pensamento; e (2) entre a ordem e a conexão das ideias e a ordem e a conexão das ideias das ideias.

À primeira forma do paralelismo intracogitativo corresponde a ideia, enquanto "[...] considerada como essência formal (ou ser formal), modo do pensamento, causa compreendida na cadeia infinita de causas 
no pensamento.” (Gueroult 8, p. 70, grifo do autor). Esta primeira forma é a responsável pela concatenação lógica de nossas ideias segundo a ordem das causas primeiras no interior do atributo pensamento, ou ordem do intelecto, que é a mesma em todos os homens, possibilitando a mente escapar da ordem fortuita das afecções do corpo ou associações de ideias. Ordem fortuita esta que possibilita ao homem passar imediatamente do pensamento de uma coisa para o pensamento de uma outra que não tem com a primeira qualquer semelhança, isto é, não tem nenhuma relação causal ou nenhuma conexão lógica. Como, por exemplo, do pensamento da palavra pomum (maçã), um romano passará imediatamente para o pensamento de uma fruta que não tem qualquer semelhança com este som articulado, nem nada de comum com ele, a não ser que o corpo desse homem foi muitas vezes afetado por estas duas coisas ao mesmo tempo: ele ouviu muitas vezes a palavra pomum ao mesmo tempo em que via a fruta (Spinoza 1, E2P18S).

À segunda forma do paralelismo intracogitativo corresponde a ideia enquanto "[...] considerada em sua forma ou natureza, como ideia da ideia, [...]" (Gueroult 8, p. 70, grifo do autor), isto é, a ideia considerada como saber ou conhecimento reflexivo. Esta segunda forma é a garantia de que "quem sabe, sabe que sabe", isto é, tem a certeza, pois a ideia da ideia não é senão a forma da ideia, enquanto é considerada como um modo do pensar sem relação com o objeto (Spinoza 1, E2P21S). Este paralelismo, considerado conjuntamente sob suas duas formas, é o fundamento da possibilidade de conhecermos a correspondência entre a ideia e o seu objeto, ou seja, é o garante da função representativa do paralelismo extracogitativo.

\section{Conclusão}

Ao expor, ainda que de forma sucinta, o percurso demonstrativo de Spinoza da mente como uma ideia do corpo e este como algo realmente existente, pressupondo uma relação entre um modo finito do atributo pensamento e um modo finito do atributo extensão, tornado possível pelo Paralelismo, apresentamos o que constitui a natureza humana em Spinoza; ou seja, o corpo, que se mantém através de todas as mudanças que afetam as partes desse corpo, está continuamente sujeito ao acaso dos encontros (occursus), ou ao impacto dos múltiplos e variados corpos a sua volta. A mente reflete estes encontros e através deles, ou das afecções corporais, conhece os corpos externos. É a ideia-afecção. É o conhecimento imaginativo, ou o conhecimento condicionado pela situação de nosso próprio corpo, por nosso temperamento, nossa experiência prévia e nossos preconceitos individuais. E é justamente a partir desta ideia de homem como ser imaginativo, que somente percebe os corpos exteriores através de seu próprio corpo, que Spinoza irá definir os afetos ou sentimentos que serão afirmados como as ideias de nossas afecções corporais.

\section{REFERÊNCIAS BIBLIOGRÁFICAS:}

1. SPINOZA, Benedictus de. Ethica/Ética. Edição bilíngue Latim-Português. Tradução e Notas de Tomaz Tadeu. Belo Horizonte: Autêntica, 2007.

2. Correspondencia. Introducción, traducción, notas y índice de Atilano Domínguez. Madri: Alianza, 1988.

3. BRUNSCHVICG, Léon. Spinoza et ses Contemporains. 5. ed. Paris: Presses Universitaires de France, 1971. (Bibliothéque de Philosophie Contemporaine).

4. DELEUZE, Gilles. Espinosa: Filosofia Prática. Tradução de Daniel Lins e Fabien Pascal Lins. Revisão técnica de Eduardo D. B. de Menezes. São Paulo: 
Escuta, 2002.

5. DELBOS, Victor. Le Problème Moral dans la Philosophie de Spinoza et dans l'Histoire du Spinozisme. Paris: Felix Alcan, 1893. Réimpr. Georg Olms, 1988.

6. O Espinosismo: Curso proferido na Sorbonne em 1912-1913. Tradução de Homero Silveira Santiago. São Paulo: Discurso, 2002.

7. DELEUZE, Gilles. Spinoza et le Problème de l'Expression. Paris: Éditions de Minuit, 1985. (Arguments).

8. GUEROULT, Martial. Spinoza. v. 2 (L'Âme). Paris: Aubier-Montaigne, 1997. (Analyse et Raisons).

\section{The conception of human nature in Benedictus Spinoza}

Abstract: Spinoza in his Ethics conceives human nature as composed by means of two of God's infinite attributes, thought and extension, or the idea and it's object, the body. Human mind as an idea and the object of this idea, the body, assume a non-causal relation between the finite mode of thought and extension. The body, while a relation composed of motion and stillness is kept through the changes that affects its parts, is continually subjected to encounters by chance (occursus), or to the impact of multiple bodies around it. Mind reflects these encounters and through them acknowledges external bodies. It's the afection-idea. It's the imaginative knowledge, or the knowledge conditioned by the situation of our own body, by our temper, our previous experience and our individual prior concepts.

Keywords: Spinoza. Ethica. Human nature. Mind. Body.

\section{NOTAS:}

1. Spinoza utiliza o termo latino Mens. Optamos por utilizar em português o termo Mente.

2. Para as citações internas da Ética indicaremos a parte citada em algarismos arábicos, seguida da letra correspondente para indicar as definições (Def), axiomas $(\mathrm{Ax})$, proposições (P), prefácios (Pref), corolários (C), escólios (S) e Apêndice (Ap), com seus respectivos números.
3. Respondendo à pergunta de Simon de Vries sobre a necessidade da experiência para verificar se a definição de um atributo é verdadeira, Spinoza responde “[...] nós não necessitamos nunca da experiência, exceto para aquelas coisas que não se podem deduzir da definição da coisa, como por exemplo, a existência dos modos, já que esta não se pode derivar da definição da coisa. [...] já que a experiência não nos ensina a essência de nenhuma coisa; [...]". (Spinoza 2, Carta X, p. 122).

4. Neste parágrafo fundamentamo-nos em Gilles Deleuze (Deleuze 4, p. 76-77).

5. Neste parágrafo fundamentamo-nos em Victor Delbos (Delbos 6, p. 84-85) e Gilles Deleuze (Deleuze 4, p. 73-74).

6. Neste parágrafo e no seguinte, estamos nos baseando e citando Gilles Deleuze: (Deleuze 4, p. 74-75 e Deleuze 7, p. 100). Deleuze interpreta o termo "indivíduo" como significando "a unidade de uma ideia e de seu objeto", baseado no escólio da proposição 21, da Parte 2 da Ética (Deleuze 7, Nota 3, p. 100). 